\title{
Tofacitinib- A First-In-Class Drug for Rheumatoid Arthritis
}

\author{
Sujithera Haridoss ${ }^{1}$, Damal Kandadai Sriram ${ }^{2}$, Melvin George ${ }^{1}$ \\ 1. Dept of Clinical Research, Hindu Mission Hospital, West Tambaram, Chennai-600045 \\ 2. Dept of Diabetology \& Endocrinology, Hindu Mission Hospital, West Tambaram, Chennai-600045
}

\begin{abstract}
Rheumatoid arthritis (RA) is a chronic, systemic and disabling autoimmune inflammatory disease characterized by inflammation of the synovial lining of the joints, tendons and periarticular structure affecting approximately $1 \%$ of the population world-wide. Tofacitinib is a novel oral Janus-kinase inhibitor approved for the treatment of RA patients as a second line therapy in those who fail to respond to methotrexate therapy. Clinical trials with tofacitinib have shown reasonable efficacy. However, the drug's greatest limitation is its potential to induce cancers and latent infections could be reactivated. Nevertheless, the drug can slow the progression of the disease and has evoked lot of interest due to the fact that it is a first in class molecule for the treatment of rheumatoid arthritis.
\end{abstract}

\section{Introduction}

Rheumatoid arthritis (RA) is an autoimmune disease of the musculoskeletal system that ischaracterized by inflammation and destruction of joints, associated with considerable morbidity and diminished quality of life[1] and imposes a substantial economic burden to patients and society[2]. RA affects approximately $1 \%$ of the worldwide population [3]. The treatment of RA involves NSAIDs, methotrexate and other DMARDs. Those patients failing to respond to these medication invariably require other biologic agents such as infliximab, etanercept, Yet there are significant challenges with the current lot of drugs that has fueled the search for better molecules with robust efficacy and acceptable safety. One of the most recent drugs to receive marketing approval by the office of the Drug Controller General of India for the treatment of rheumatoid arthritis is tofacitinib, which was approved in April 2016. We have attempted to review tofacitinibwhich includes the mechanism of action, efficacy, safety and pharmacokinetics of the drug.

\section{Mechanism of Action}

Tofacitinib (CP-690,550) is a Janus kinase inhibitor that is a targeted immunomodulator and has disease-modifying potential in Rheumatoid arthritis[4,5]Optimizationof a pyrrolopyrimidine-based series of inhibitors represented by CP-352,664 led to identification of tofacitinib. [6] The drug inhibits signaling through JAK1 and JAK3 /STATpathway with selectively reduced cellular potency of JAK2.[7]Tofacitinib inhibits signaling by heterodimeric receptors bound among JAK1 and JAK3 with functional selectivity of receptors that signal via JAK2, which blocks signaling for several cytokines and interleukins. Autoimmune diseases can be induced by $\mathrm{CD}^{+}{ }^{+}$T cells that produce IFN- $\gamma$ (Th1 cells), IL-17 (Th17 cells)[8].Keisuke et al has suggested that tofacitinib directly suppressed the production of IL-17 and IFN- $\gamma$ and proliferation of $\mathrm{CD} 4^{+} \mathrm{T}$ cells. However, the precise mechanisms by which JAK inhibition improves inflammatory immune responses remain unclear.

\section{Efficacy}

The clinical efficacy and safety of tofacitinib was tested in five Phase III, randomized, double blind, placebo controlled studies ORAL Step(A3921044; NCT00847613), ORAL Solo (A3921045;NCT00814307), ORAL Sync (A3921046; NCT00856544) and ORAL Standard (A3921064; NCT00853385).The efficacy parameters assessed to test the efficacy of Tofacitinib includes American College of Rheumatology (ACR) 20/50/70 response rates; the percentage of patients with a Disease Activity Score for 28-joint counts based on the erythrocyte sedimentation rate (DAS28-4[ESR]) of less than 2.6 (with scores ranging from 0 to 9.4 and higher scores indicating more disease activity); Health Assessment Questionnaire-Disability Index(HAQDI), which range from 0 to 3 , with higher scores indicating greater disability.

The ORALSolo and ORAL Sync study included patients who have inadequate response to DMARD, while the ORALScan and ORALStandard study had patients with poor response to methotrexate and the ORALStep study included patients who had failed to respond to TNF alpha inhibitors.[9].Tofacitinib showed favorable ACR-20/50/70 response rate and improvement in HAQ-DI scorewhen compared to placebo for all the Phase III studies. Though there was significant heterogeneity among the studies stated,the odds of tofacitinib treated patients who achieved the efficacy criteria was significantly higher in the placebo group. The significant 
difference between tofacitinib group and placebo group in ACR response rate and HAQ-DI score were consistent with the previous trials.[11]

Table 1 Summary of phase III clinical studies with tofacitinib

\begin{tabular}{|c|c|c|c|c|c|c|c|}
\hline $\begin{array}{l}\text { Phase III } \\
\text { trials }\end{array}$ & $\begin{array}{l}\text { Duration / } \\
\text { Response } \\
\text { rate }\end{array}$ & $\begin{array}{l}\text { Sample } \\
\text { size }\end{array}$ & Study Arms & $\begin{array}{l}\text { ACR20 } \\
\text { Respon } \\
\text { se rate }\end{array}$ & $\begin{array}{l}\text { DAS28- } \\
4(E S R)<2.6\end{array}$ & HAQ-DI & Safety \\
\hline $\begin{array}{l}\text { Burmester } \\
\text { GR et } \\
\text { al,2013 }\end{array}$ & $\begin{array}{l}\text { 6month/ } \\
\text { Month } 3\end{array}$ & 399 & $\begin{array}{l}\text { Tofacitinib 5mg, } \\
\text { Tofacitinib } 10 \mathrm{mg} \\
\text { combined Placebo }\end{array}$ & $\begin{array}{l}41.7 \\
48.1 \\
24.4\end{array}$ & $\begin{array}{l}6.7 \\
8.8 \\
1.7\end{array}$ & $\begin{array}{l}-0.43 \\
-0.46 \\
-0.18\end{array}$ & $\begin{array}{l}\text { Increasedintransminase levels, } \\
\text { cholesterol and serum } \\
\text { creatinine, and decreased in } \\
\text { neutrophil andhemoglobin } \\
\text { levels }\end{array}$ \\
\hline $\begin{array}{l}\text { Roy } \\
\text { Fleischman } \\
\text { n et al, } \\
2012\end{array}$ & $\begin{array}{l}\text { 6months/ } \\
\text { Month } 3\end{array}$ & 611 & $\begin{array}{l}\text { Tofacitinib 5mg, } \\
\text { Tofacitinib } 10 \mathrm{mg} \\
\text { combined Placebo }\end{array}$ & $\begin{array}{l}59.8 \\
65.7 \\
26.7\end{array}$ & $\begin{array}{l}5.6^{\mathrm{a}} \\
8.7^{\mathrm{a}} \\
4.4\end{array}$ & $\begin{array}{l}-0.50 \\
-0.57 \\
-0.19\end{array}$ & $\begin{array}{lllr}\begin{array}{l}\text { Increase } \\
\text { reductions } \\
\text { counts. }\end{array} & & & \text { LDL } \\
\text { neutrophil } \\
\end{array}$ \\
\hline $\begin{array}{l}\text { van } \\
\text { Vollenhove } \\
\text { n RFet al, } \\
2012\end{array}$ & $\begin{array}{l}\text { 12month/ } \\
\text { Month } 6\end{array}$ & 717 & $\begin{array}{l}\text { Tofacitinib 5mg, } \\
\text { Tofacitinib } 10 \mathrm{mg} \\
\text { Adalimumab } \\
\text { 40mg weekly and } \\
\text { Placebo }\end{array}$ & $\begin{array}{l}51.5 \\
52.6 \\
47.2 \\
28.3\end{array}$ & $\begin{array}{l}6.2 \\
12.5 \\
6.7 \\
1.1 \\
\end{array}$ & $\begin{array}{l}-0.55 \\
-0.61 \\
-0.49 \\
-0.24\end{array}$ & $\begin{array}{l}\text { increase in both LDL \& HDL } \\
\text { and reductions in neutrophil } \\
\text { counts }\end{array}$ \\
\hline $\begin{array}{l}\text { van der } \\
\text { Heijde D et } \\
\text { al, } 2013\end{array}$ & $\begin{array}{l}\text { 24month/ } \\
\text { Month } 3\end{array}$ & 797 & $\begin{array}{l}\text { Tofacitinib 5mg, } \\
\text { Tofacitinib 10mg } \\
\text { combined Placebo }\end{array}$ & $\begin{array}{l}51.5 \\
61.8 \\
25.3\end{array}$ & $\begin{array}{l}7.2^{\mathrm{b}} \\
16 \\
1.6\end{array}$ & $\begin{array}{l}-0.4 \\
-0.54 \\
-0.15\end{array}$ & $\begin{array}{l}\text { increase in LDL and } \\
\text { reductions in neutrophil } \\
\text { counts }\end{array}$ \\
\hline
\end{tabular}

Abbrevations:ACR,American College of Rheumatology; HAQ-DI,Health Assessment Questionnaire-Disability Index;DAS,Disease Activity Score in 28 joints.ESR: Erythrocyte sedimentation rateLDL: Low-density lipoproteinHDL: High-density lipoprotein

${ }^{a}$ Not statistically significant; ${ }^{b}$ statistical significance was not declared

\section{Pharmacokinetics}

Greater clinical response was reported for tofacitinib $5 \mathrm{mg}$ and $10 \mathrm{mg}$ twice daily. When a single 50-mg (14)C-labeled tofacitinib dose prescribed to the subjects, the mean (standard deviation) total percentage of administered radioactive dose recovered was $93.9 \%( \pm 3.6)$, with $80.1 \%( \pm 3.6)$ in the urine $(28.8 \%$ parent $)$, and $13.8 \%( \pm 1.9)$ in feces $(0.9 \%$ parent $)$. The drug was absorbed, with plasma concentrations and total radioactivity peaking at around 1 hour after oral administration.Tofacitinib is highly protein bound and metabolized by CYP3A4, which accounts for $70 \%$ of the hepatic clearance and remaining $30 \%$ are renally excreted. The preponderant metabolic pathways of tofacitinib includes oxidation of the pyrrolopyrimidine and piperidine rings, oxidation of the piperidine ring side-chain, $\mathrm{N}$-demethylation and glucuronidation. The drug has a half life of 3.5 hrs.[12]

\section{Safety}

Patients on tofacitinib are unsurprisingly at a greater risk of infections and this has to be borne in mind before prescribing tofacitinib. Herpes zoster, opportunistic infections and tuberculosis were the serious infections that were seen at a higher incidence with tofacitinib. The most common treatment-related infections were bronchitis $(1.6 \%)$, nasopharyngitis $(1.4 \%)$, upper respiratory tract infection $(1.4 \%)$, urinary tract infection $(1.4 \%)$, and oral herpes virus infection $(1.4 \%)$.[11,13]The common laboratory changes observed after treatment of tofacitinib includes sporadic increases in transaminase levels, increases in cholesterol and serum creatinine levels, and decrease in neutrophil and hemoglobin levels[11]Tofacitinib treated patients had a low incidence of $\mathrm{CV}$ events in phase III trials, despite their elevation in cholesterol level.[14]For the patients receiving tofacitinib the most frequently reported adverse events that were mild in severity include headache, diarrhea, nausea, urinary tract infection, upper respiratory tract infection, nasopharyngitis, influenza and cough.

\section{Current Status}

Tofacitinib is the first oral JAK inhibitor developed for the treatment of RA in the late 2012. Some of the issues that need further clarity with tofacitinib includes efficacy of the drug as monotherapy, head-toheadcomparison with other BDMARD(biologic-D-MARD) such as adalimumab,etanercept,certolizumab and tocilizumab. Most biologic agents need to be administered parenterally either as subcutaneous as in etanercept, adalimumab or intravenous as in certolizumab, rituximab and infliximab. In contrast, tofacitinib has a distinct advantage of oral administration which would improve the patient adherence. 


\section{Conclusion}

Tofacitinib is a pioneering oral Janus kinase inhibitor that has recently entered the burgeoning market for the treatment of rheumatoid arthritis. In the active RA patients, for whom the response was inadequate with respect to DMARDs, the addition of tofacitinibdemonstrated significant efficacy over placebo. Patients on tofacitinib are at a greater predilection to develop infections owing to the drug's property to interfere with the immunologic defenses. Although the pharmacological options for the treatment of rheumatoid arthritis is flooded with a gamut of options, there is a definite need for cheaper, effective medication with reasonable safety margin. Tofacitinib while not clearing the cost hurdle does appear to have value in minimizing the symptoms of the disease. Post marketing studies and studies comparing the drug with other biologic agents would help us understand the drug better in the days ahead to see if this could carve a niche for itself in the pharmacotherapy of rheumatoid arthritis.

\section{References}

[1]. Hochberg MC, Johnston SS, John AK. The incidence and prevalence of extraarticular and systemic manifestations ina cohort of newly-diagnosed patients with rheumatoid arthritis between 1999 and2006. Curr Med Res Opin 2008;24:469-80

[2]. Strand V and Singh JA. Improved Health related quality of life with effective disease-modifying antirheumatic drugs: evidencefrom randomized controlled trials.Am J Manag Care 2007;13(9):237-251.

[3]. Gibofsky .AOverview of epidemiology, pathophysiology and diagnosis of rheumatoid arthritis.Am J Manag Care. 2012;(13):295302.

[4]. Ghoreschi K, Jesson MI, Li X, Lee JL, Ghosh S, AlsupJW,et al, Modulation of innate and adaptive immune responses by tofacitinib (CP-690,550).J Immunol. 2011;186(7):4234-4243.

[5]. Ghoreschi K, Laurence A and O'Shea JJ.Janus kinases in immune cellsignaling. Immunol Rev 2009;228:273-287.

[6]. Flanagan ME, Blumenkopf TA, Brissette WH, Brown MF, Casavant JM, Shang-Poa C et al Discovery of CP-690,550: a potent and selective Janus kinase (JAK) inhibitor for the treatment of autoimmune diseases and organ transplant rejection $\mathrm{J}$ Med Chem. 2010;53(24):8468-8484.

[7]. Meyer DM, Jesson MI, Li X, Elrick MM, Funckes-Shippy CL, Warner JD, et al; Anti-inflammatory activity and neutrophil reductions mediated by the JAK1/JAK3 inhibitor, CP-690,550, in rat adjuvant-induced arthritis.JInflamm (Lond).2010;7:41.

[8]. DamskerJ.M,Hansen A.M, and Caspi R.R. Th1 and Th17 cells:adversaries and collaborators. Ann N Y Acad Sci 2010;1183: 211221.

[9]. Charles-SchoemanC,Burmester G, Nash P, A F Zerbini C, Soma K, Kwok K Efficacy and safety of tofacitinib following inadequate response to conventional synthetic or biological disease-modifying antirheumatic drugs.Ann Rheum Dis.2016;75(7):1293-301.

[10]. Fleischmann R, Cutolo M, GenoveseMC, Lee EB, Kanik KS, Sadis Set al. Phase IIB dose-ranging study ofthe oral JAK inhibitor tofacitinib (CP-690,550) or adalimumab monotherapy versusplacebo in patients with active rheumatoidarthritis with an inadequate responseto disease-modifying antirheumatic drugs.Arthritis Rheum 2012;64(3):617-29.

[11]. Kremer JM, Cohen S, Wilkinson BE. A phase IIB dose-ranging study of theoral JAK inhibitor tofacitinib (CP-690,550)versus placebo in combination with background methotrexate in patients with activerheumatoid arthritis and inadequate response to methotrexate alone. ArthritisRheum 2012;64:970-81.

[12]. Dowty ME, Lin J, Ryder TF, Wang W, Walker GS, Vaz A et al, The pharmacokinetics, metabolism, and clearance mechanisms of tofacitinib, a janus kinase inhibitor, in humans.DrugMetabDispos.2014;42(4):759-73.

[13]. Cohen S B,PaulEmery,Maria W. Greenwald et al.,Rituximab for rheumatoid arthritis refractory to anti-tumor necrosis factor therapy: Results of a multicenter, randomized, double-blind, placebo-controlled, phase III trial evaluating primary efficacy and safety at twenty-four weeks.arthritis and rheumatology:2006(54);2793-2806.

[14]. Charles-Schoeman C, Wicker P, Miguel A.Gay G,Cardiovascularsafety findings inpatientswithrheumatoidarthritistreatedwith tofacitinib, anoralJanuskinaseinhibitor.SeminarsinArthritisandRheumatism 2016;46:261-271.

[15]. Ho Lee Y, Bae S-C. Comparative efficacy and safety of tocilizumab, rituximab, abatacept and tofacitinib in patients with active rheumatoid arthritis that inadequately responds to tumor necrosis factor inhibitors: a Bayesian network meta-analysis of randomized controlled trials. international journal of rheumatic disease.2016;(19):1103-1111. 